\title{
СРАВНЕНИЕ НАГРУЗОЧНОЙ СПОСОБНОСТИ ГОЛОВОК ВИНТА В ЗАВИСИМОСТИ ОТ ФОРМЫ ПАЗА
}

\author{
Кравченко Р. В. ${ }^{1}$, Богдан Д. И. ${ }^{1}$, Поваляев С. И. ${ }^{1}$ \\ ${ }^{1}$ Харківський національний автомобільно-дорожній університет
}

Аннотация. Для ремонта автомобиля и других работ с резьбовым крепежом часто используется удобный инструмент - ториевые головки. В настоящей статье рассмотрена нагрузочная способность двух самых распространенных форм ториевых головок, а именно головки Тогх и головки Нех.

Ключевые слова: ториевая головка, Тогх, нагрузка, расчет, МКЭ, напряжения.

\section{Введение}

В настоящее время в автомобильной промышленности широко распространены торцевые головки. В процессе ремонта и наладки техники много времени занимает откручивание и закручивание различных крепежей, гаек и болтов. Как раз для этой работы используются торцевые головки, которые часто используются, если крепежные элементы находятся в труднодоступных местах.

\section{Анализ публикаций}

Существует множество видов крепежных элементов в зависимости от формы торцевой лунки $[1,2]$. В последние годы в зарубежном автомобилестроении всё более широкое применение находят крепежные элементы с фасонной головкой типа «TORX» [3]. Данные головки могут иметь различную форму торцевой лунки, размеры и технические характеристики $[4,5]$. В связи с этим был проведен ряд исследований, посвященных изучению механических свойств таких торцевых головок как в процессе их эксплуатации, так и при их производстве.

В работе [6] описана серия экспериментов с целью оценки влияния формы и размеров торцевой лунки на прочность болтов. Установлены условия разрушения болтов по резьбовому участку без разрушения головки.

Авторами работ [7-8] рассмотрены вопросы повышения эффективности изготовления болтов с фланцем холодной штамповкой путем совершенствования технологии и конструкций инструмента. Пути усовершенствования конструкции болтов с головкой типа «TORX» были описаны в работе [9].

Цель и постановка задачи

Целью данной работы является проведение сравнительного анализа наиболее распространенной шестигранной торцевой го- ловки и торцевой головки Torx, для оценки их эксплуатационных характеристик.

Для достижения поставленной задачи необходимо определить напряженнодеформированное состояние как рассматриваемых торцевых головок, так и соответствующего инструмента.

\section{Обзор геометрии, а также виды и} характеристики головок "Torx"

Торцевая головка представляет собой слесарно-монтажный инструмент который имеет насадку в виде шестиконечной звезды (рис. 1.), за счет которого можно достичь оптимального приложения крутящего момента к резьбовому соединению.

Обозначается как Т или ТХ.

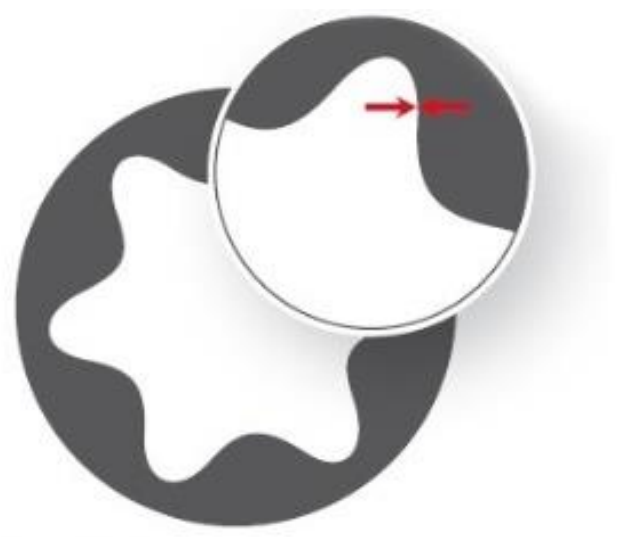

\section{TORX}

Рис. 1. Форма углубления Torx

Зарегистрирован товарный знак фирмой Textron Fastening Systems (ныне Acument Global Technologies). Официальное название, зафиксированное в стандарте ISO 10664 углубление звездообразное под ключ для болтов и винтов.

Шлиц разработан компанией Textron в 1967 году. 
На данный момент изготавливаются различные крепежные изделия с углублением Torx, pис. $2[6,7]$.

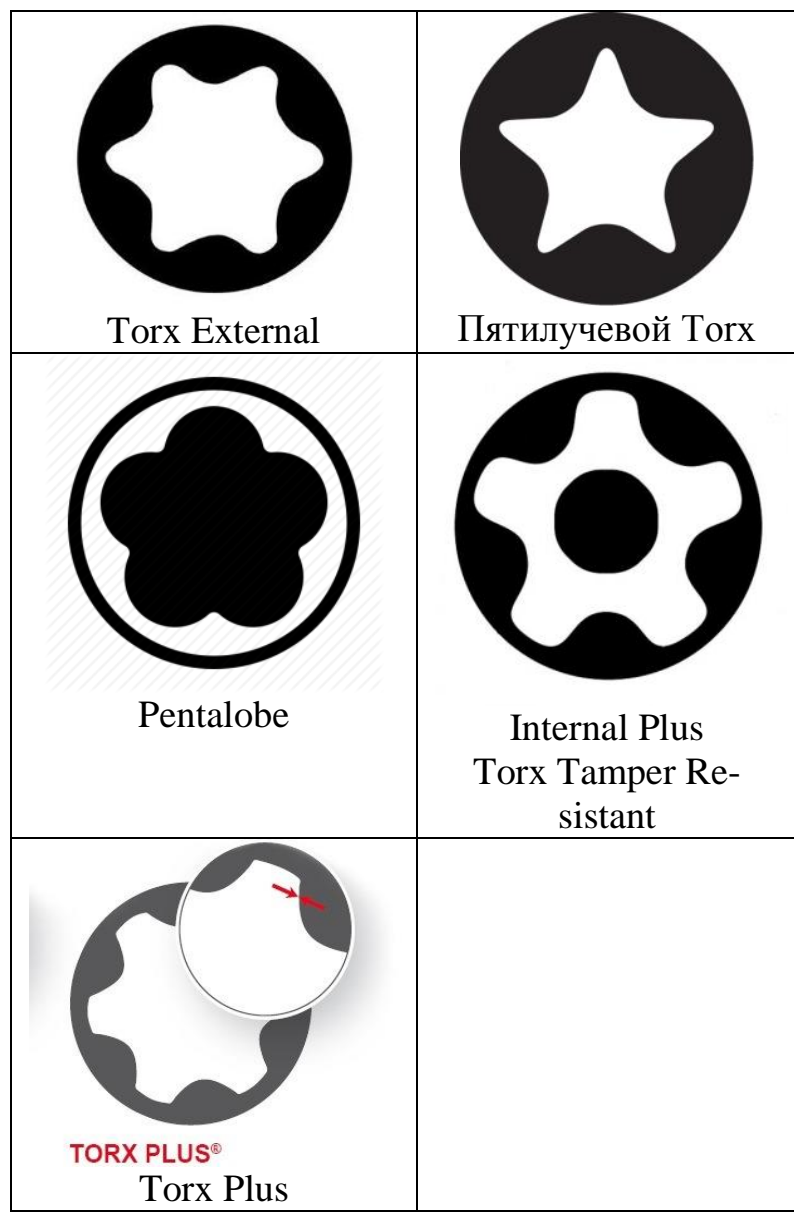

Рис. 2. Различные формы углублений Torx

Torx External обозначается как Е. Представляет собой инвертированный Torx. Крепеж имеет головку в форме звезды, а инструмент имеет соответствующее углубление. Используется, как правило в автомобилях для уменьшения размера головки болта. Антивандальным не бывает.

Torx Tamper Resistant (антивандальный) обозначается как TR. В середине шлица имеется штырёк и соответствующее этому штырьку отверстие у отвёртки или ключа. Другие названия - Security Torx, pin-in Torx.

Пятилучевой Torx. Один из антивандальных вариантов. Отдельный шлиц в форме ромашки, используемый в электронике Apple.

Torx Plus. Улучшенный шлиц со срезанными концами звезды. Обозначается как IP (Internal Plus).

Torx Plus External - внешний вариант Torx Plus. Обозначается как EP (External Plus). Также имеет мини-варианты от Н7ЕР до H2EP.
Антивандальная версия Torx Plus имеет пять лучей и штырек в центре углубления. В стандарте маркировка не указана, но может встречаться как TS или IPR.

\section{Маркировка и размеры}

Ключи и отвёртки имеют маркировку $\mathrm{T}$ или ТХ с номером шлица - 1, 2, 3, 4, 5, 6, 7, $8,9,10,15,20,25,27,30,40,45,50,55,60$, $70,80,90,100$, таблица 1.

Таблица 1 - Приблизительные размеры и моменты затяжки [8-9]

\begin{tabular}{|c|c|c|c|c|}
\hline Номер & Дюймы & MM & $\begin{array}{c}\text { Момент } \\
\text { затяжки, } \\
\mathrm{H} \cdot \mathrm{M}\end{array}$ & $\begin{array}{c}\mathrm{E} \\
\text { Torx }\end{array}$ \\
\hline $\mathrm{T} 1$ & 0,031 & 0,81 & $0,02-0,03$ & \\
\hline $\mathrm{T} 2$ & 0,036 & 0,93 & $0,07-0,09$ & \\
\hline T3 & 0,046 & 1,1 & $0,14-0,18$ & \\
\hline $\mathrm{T} 4$ & 0,050 & 1,28 & $0,22-0,28$ & \\
\hline T5 & 0,055 & 1,42 & $0,43-0,51$ & \\
\hline \multicolumn{5}{|l|}{ T5.5 } \\
\hline T6 & 0,066 & 1,7 & $0,75-0,90$ & \\
\hline $\mathrm{T7}$ & 0,078 & 1,99 & $1,4-1,7$ & \\
\hline T8 & 0,090 & 2,31 & $2,2-2,6$ & \\
\hline T9 & 0,098 & 2,5 & $2,8-3,4$ & \\
\hline T10 & 0,107 & 2,74 & $3,7-4,5$ & \\
\hline T15 & 0,128 & 3,27 & $6,4-7,7$ & \\
\hline T20 & 0,151 & 3,86 & $10,5-12,7$ & E4 \\
\hline $\mathrm{T} 25$ & 0,173 & 4,43 & $15,9-19$ & E5 \\
\hline $\mathrm{T} 27$ & 0,195 & 4,99 & $22,5-26,9$ & \\
\hline T30 & 0,216 & 5,52 & $31,1-37,4$ & E6 \\
\hline \multicolumn{5}{|l|}{ T35 } \\
\hline $\mathrm{T} 40$ & 0,260 & 6,65 & $54,1-65,1$ & E8 \\
\hline T45 & 0,306 & 7,82 & $89-103,2$ & \\
\hline T47 & GM-Style & & & \\
\hline T50 & 0,346 & 8,83 & $132-158$ & E10 \\
\hline T55 & 0,440 & 11,22 & $218-256$ & E12 \\
\hline T60 & 0,519 & 13,25 & $379-445$ & E16 \\
\hline T70 & 0,610 & 15,51 & $630-700$ & E18 \\
\hline T80 & 0,690 & 17,54 & $943-1048$ & E20 \\
\hline T90 & 0,784 & 19,92 & $1334-1483$ & \\
\hline T100 & 0,871 & 22,13 & $1843-2048$ & E24 \\
\hline
\end{tabular}

Ключи и отвёртки со шлицем Torx Tamper Resistant после основной маркировки дополнительно обозначаются TR.

У ключей и отвёрток со шлицем Torx Plus сначала указывается номер шлица, а после вместо Т или TX обозначается буквами IP.

Ключи и отвёртки со шлицем Torx Plus Tamper Resistant после основной маркировки дополнительно обозначаются TS. 
Размер определяется по окружности описанной по вершинам звездочки инструмента (для версии Е - болта).

\section{Обзор геометрии, а также виды и характеристики шестигранных головок}

В отличии от головок Torx головка крепёжного изделия имеет цилиндрическую форму с шестигранным углублением, рис. 3.

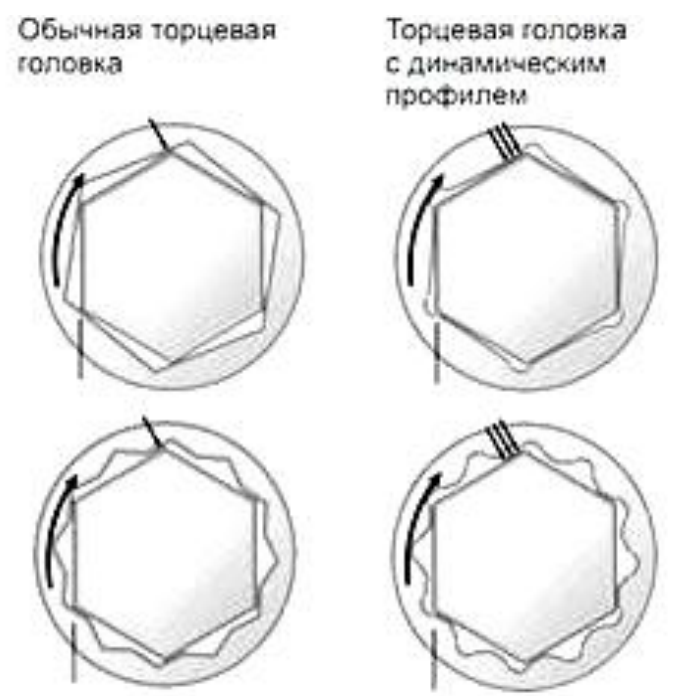

Рис. 3. Форма головки с шестигранным профилем
Профиль обеспечивает наилучший охват крепежа (имеет большую площадь пятна контакта), полную и равномерную передачу усилия на него.

Для работы со шлицами данного вида используется шестигранный или же бита с соответствующим наконечником.

Номинальным размером шлица и ключа является расстояние между противоположными параллельными гранями шестигранника, которое выражается в миллиметрах (при этом, для ключа методику измерения и допуски см. ГОСТ 8560-78) или долях дюйма.

Однако позиционирование и использование такой головки затруднено в стесненных условиях - для перестановки воротка или иного приспособления нужно провернуть инструмент хотя бы на 60 градусов. Проблему решает инструмент с трещоткой, либо применение 12-гранных головок.

Проведем сравнительную характеристику шестигранной головки и головки Torx, таблица 2.

Таблица 2 - Основные недостатки торцевых головок

\begin{tabular}{|l|l|}
\hline \multicolumn{1}{|c|}{ Вид шлица } & \multicolumn{1}{|c|}{ Оставшиеся недостатки } \\
\hline 1. Шестигранный & $\begin{array}{l}\text { Шестигранный шлиц способен передавать высокий момент вра- } \\
\text { щения на крепежный элемент только на протяжении недолгого } \\
\text { времени, затем в нем появлются небольшие вмятины и увеличи- } \\
\text { вается угол холостого хода инструмента. }\end{array}$ \\
\hline 2. Звездообразный (Тогх) & $\begin{array}{l}\text { Все еще не обеспечивает полного контакта рабочего наконечника } \\
\text { инструмента с головкой крепежного элемента, но позволяет вы- } \\
\text { полнять монтаж под небольшим углом к оси крепежного элемента } \\
\text { без потери момента вращения. }\end{array}$ \\
\hline
\end{tabular}

Для корректного сравнения принимаем близкие размеры шлица Torx и Нех. Для расчета на прочность примем размер шлица Torx равен T40 (рис. 4), a размер шестигранника HEX равным 6 мм.

Для обеспечения совместимости предусмотрен зазор в соединениях равный 0,1 мм.

Для сравнительного анализа модели соединений нагружались одинаковым небольшим тестовым крутящим моментом. Такая постановка задачи позволяет гарантировано находится в зоне упругих деформаций и адекватно сравнивать различную геометрию шлицев. Анализ нагрузочной способности шлица выполнен методом конечных элементов. Головка винта была зафиксирована, а к вставленной с зазором 0,1 мм бите прикладывался крутящий момент 1 Нм.

Распределение эквивалентного напряжения по телу головки болта и биты представлено на рис 5.

Такой же расчет был выполнен и для шлица с формой шестигранника. 

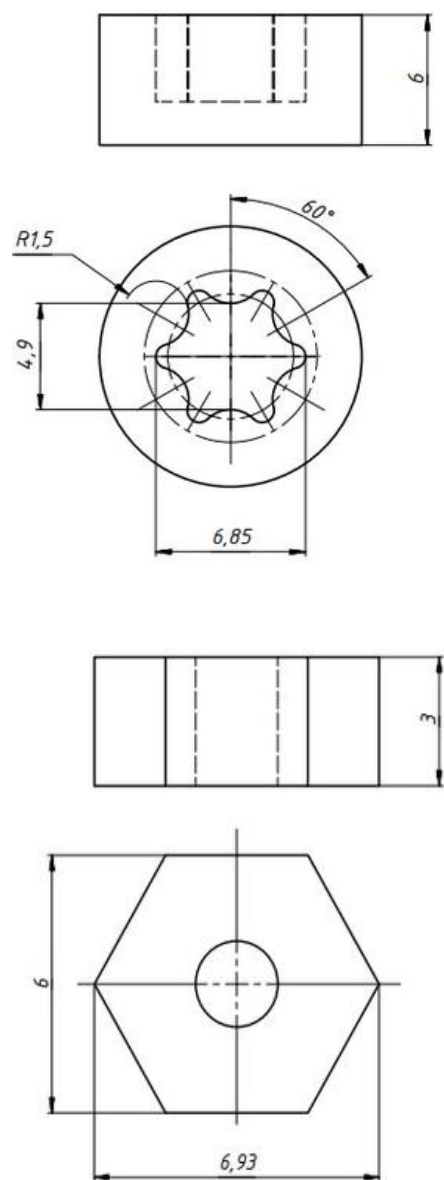
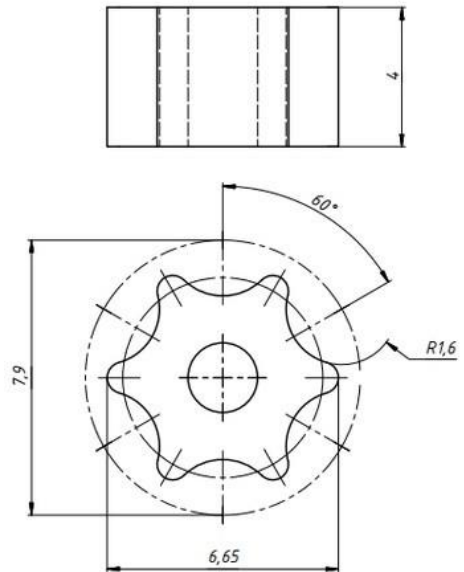

a
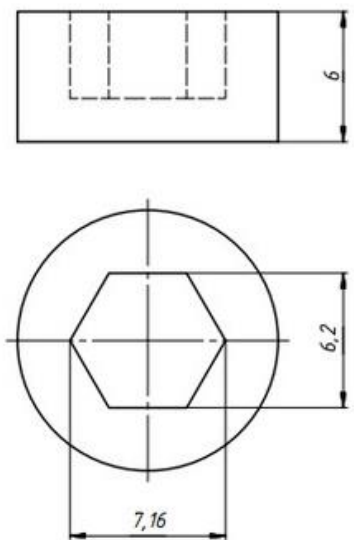

6

Рис. 4. Размеры головок и пазов: a - головка и паз типа Torx; б - шестигранная головка и паз

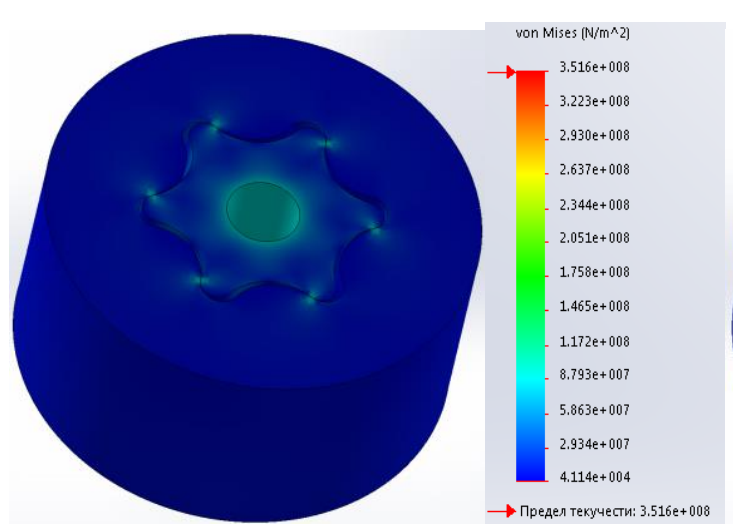

a

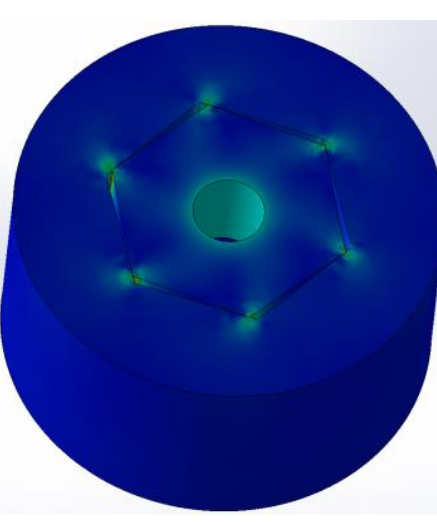

6

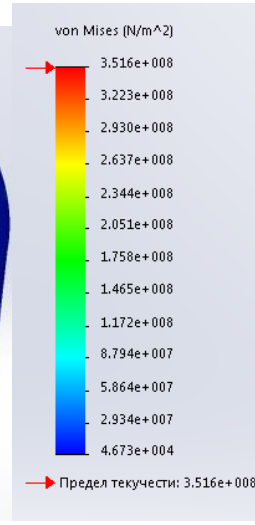

Рис. 5. Эквивалентные напряжения торцевых головок: a - головка типа Torx; б - шестигранная головка
Как видно из рисунка 5а, 5б, в головке типа Нех зона с эквивалентными напряжениями превышающими 20 МПа имеет большую площадь. При этом также для шестигранной головки присутствуют зоны концентрации напряжений на вершинах со значениями до 35 МПа. Такая ситуация обусловлена геометрией контакта биты и шлица. В случае с головкой Torx имеет место контакт выпуклой и вогнутой поверхностей, а в случае с головкой Нех в следствии наличия зазора имеет место контакт близкий к точечному, что обуславливает повышенную концентрацию напряжений.

Помимо повышенной нагрузочной способности головки типа Torx, обладают следующими эксплуатационными функциональными преимуществами, таблица 3. 
Таблица 3 - Перечень функциональных преимуществ Тогх

\begin{tabular}{|l|c|c|}
\hline \multicolumn{1}{|c|}{ Преимущества } & $\begin{array}{c}\text { Шести- } \\
\text { гранный }\end{array}$ & Тогх \\
\hline $\begin{array}{l}\text { Минимизация риска вы- } \\
\text { скальзывания инструмента }\end{array}$ & + & + \\
\hline $\begin{array}{l}\text { Пригодность для использо- } \\
\text { вания в автоматизирован- } \\
\text { ных процессах сборки }\end{array}$ & + & + \\
\hline Угол приложения силы & 60 & 15 \\
\hline $\begin{array}{l}\text { Полнота контакта наконеч- } \\
\text { ника инструмента с голов- } \\
\text { кой крепежного элемента }\end{array}$ & - & + \\
\hline $\begin{array}{l}\text { Отсутствие необходимости } \\
\text { ограничения вращательно- } \\
\text { го усилия инструмента на } \\
\text { завершающем этапе }\end{array}$ & + & + \\
\hline $\begin{array}{l}\text { Высокая степень передачи } \\
\text { момента вращения от ин- } \\
\text { струмента на крепежный } \\
\text { элемент }\end{array}$ & - & + \\
\hline $\begin{array}{l}\text { Наличие соответствующих } \\
\text { рабочих наконечников для } \\
\text { инструмента на рынке }\end{array}$ & + & + \\
\hline
\end{tabular}

\section{Выводы}

Смоделировав зацепление двух типов бит была проанализирована нагрузочная способность соединений типа Нех и Torx. Выявлены зоны локализации напряжений для готовок типа Hех и Torx. Определены причины концентрации повышенных напряжений для соединения типа Нех. Учитывая большую нагрузочную способность соединений Torx и прочие их эксплуатационные преимущества следует отметить хорошую перспективу использования этих соединений для крепежных изделий в автомобильной промышленности.

\section{Литература}

Шлиц крепежного изделия. URL: https://trusty-tools.ru/article/shlic-krepezhnogoizdeliya/ (дата звернення 14.11.2019).

2. Шлиц и его виды часть 2. URL: https://gngroup.ru/article/shlic-i-ego-vidy-chast2/ (дата звернення 14.11.2019).

3. Железков О. С., Титов А. В., Артюхин В. И., Закиров Д. М., Сабадаш А. В. Тенденции и проблемы производства крепежных изделий прогрессивной конструкции. Труды пятого конгресса прокатчиков. М.: Черметинформация, 2004. С. 414-417.

4. Torx.

URL: https://www.turkaramamotoru.com/ru/Torx131438.html (дата звернення 14.11.2019).

5. Torx. URL: https://wiki2.org/ru/Torx (дата звернення 14.11.2019).

6. Железков О. С., Ширяев О. П., Малаканов С. А., Морозов Н. П., Колесников В. Д.
Влияние торцевой лунки на прочность соединения головки со стержнем болта. Качество в обработке материалов. Магнитогорск, 2015. №2 (4). C. 48-50.

7. Кадошников В. И., Решетникова Е. С., Решетников Л. В., Кочуков С. В. Совершенствование инструментов и математическое моделирование процесса формирования головок фланцевых болтов. Вестник МГТУ им. Г.И. Носова, 2008. № 2. C. 52-56.

8. Железков О. С., Галиахметов Т. Ш., Стеблянко В. Л. Определение энергосиловых параметров процесса штамповки головок болтов с торцевой лункой. Вестник МГТУ им. Г.И. Носова, 2017. № 15. С. 35-38.

9. Закиров Д. М., Сабадаш А. В. Усовершенствование конструкции болтов с головкой типа «TORX». Вестник МГТУ им. Г.И. Носова, 2003. №. 5. C. 34-37.

\section{References}

1. Шлиц крепежного изделия. [Slot of threaded part]. Retrived from: https://trustytools.ru/article/shlic-krepezhnogo-izdeliya/ (accessed: 14.11.2019).

2. Шлиц и его виды часть 2. [Slot and its kinds part 2]. Retrived from: https://gngroup.ru/article/shlic-i-ego-vidy-chast2/ (accessed: 14.11.2019).

3. Zhelezkov O. S., Titov A. V., Artjuhin V. I., Zakirov D. M., Sabadash A. V. (2004) Tendencii i problemy proizvodstva krepezhnyh izdelij progressivnoj konstrukcii [Trends and problems of threaded parts of progressive design production]. Trudy pjatogo kongressa prokatchikov. M.: Chermetinformacija, 414-417 [in Russian].

4. Torx. Retrived from: https://www.turkaramamotoru.com/ru/Torx131438.html (accessed: 14.11.2019).

5. Torx. Retrived from: https://wiki2.org/ru/Torx (accessed: 14.11.2019).

6. Zhelezkov O. S., Shirjaev O. P., Malakanov S. A., Morozov N. P., Kolesnikov V. D. (2015) Vlijanie torcevoj lunki na prochnost' soedinenija golovki so sterzhnem bolta [The effect of the end hole on the strength of the connection of the head with the bolt shaft]. Kachestvo v obrabotke materialov. Magnitogorsk, 2 (4), 48-50 [in Russian].

7. Kadoshnikov V. I., Reshetnikova E. S., Reshetnikov L. V., Kochukov S. V. (2008) Sovershenstvovanie instrumentov i matematicheskoe modelirovanie processa formirovanija golovok flancevyh boltov [Improving tools and mathematical modeling of the process of forming the heads of flange bolts]. Vestnik MGTU im. G.I. Nosova, 2, 52-56 [in Russian].

8. Zhelezkov O. S., Galiahmetov T. Sh., Stebljanko V. L. (2017) Opredelenie jenergosilovyh parametrov processa shtampovki golovok boltov s torcevoj lunkoj [Determination of energy-power parameters in the process of stamping the heads of bolts with an end hole]. Vestnik MGTU im. G.I. 
Nosova, 15, 35-38 [in Russian].

9. Zakirov D. M., Sabadash A. V. (2003) Usovershenstvovanie konstrukcii boltov s golovkoj tipa «TORX» [Improvement of the «TORX» head bolt design]. Vestnik MGTU im. G.I. Noso$v a, 5,34-37$ [in Russian].

Кравченко Роман Владимирович ${ }^{1}$, студент, тел. 380501541902, romankravchenko1996@gmail.com

Богдан Дмитрий Иванович ${ }^{1}$, к.т.н., доцент кафедры деталей машин и теории механизмов и машин, тел. 0963103000, Phd.bogdan@gmail.com

Поваляев Сергей Иванович ${ }^{1}$, к.т.н., доцент кафедры деталей машин и теории механизмов и машин, тел. 380971992331, Povalyaevsi@ukr.net

${ }^{1}$ Харьковский национальный автомобильнодорожный университет, 61002, Украина, г. Харьков, ул. Ярослава Мудрого, 25.

Порівняння здатності до навантаження голівок гвинтів в залежності від форми пазу

Анотація. Вступ. Для ремонту автомобілів та інших робіт з різьбовими кріпленнями часто використовується зручний інструмент - ториеві головки. Широкого поширення набули різні форми шліиів, ториевих головок та гвинтів. У статті описані основні геометричні розміри, номенклатура та застосування шлічів Нех і Torx. Перелічено переваги та недоліки кожного. Наведено історію формування діючого стандарту для класифікаиії иліців. Мета. Метою даної роботи є проведення порівняльного аналізу найбільш використовуваної головки з шестигранним пазом та головки з пазом Тогх для очінки їх експлуатаційних характеристик. Методика. Розглядається контакт інструменту з ториевою головкою з точки зору контакту сполучених поверхонь, аналізується картина розподілу еквівалентних напружень в головиі гвинта, щуо виникають під дією крутного моменту, прикладеного до інструменту. Наведено тривимірні діаграми еквівалентних напружень. Розглянуто декілька варіантів сполучень Torx. 1) Torx External - зовнішній Torx. Використовується для зменшення розміру головки болma. 2) Torx Tamper Resistant-антивандальна версія, позначається як TR. 3) П'ятипроміневий Torx - ие один із антивандальних варіантів. 4) Pentalobe окремий ромашкоподібний шліи, який використовується в електронічі Apple. 5) Torx Plus - покращений шліи у вигляді зірки. Позначається як IP (Internal Plus). Інструмент Torх не може праџювати з обладнанням Torx Plus. 6) Torx Plus External зовнішня версія Torx Plus. Позначається як ЕP (Зовнішній плюс). Антивандальна версія Torx Plus має n'ять промінів $і$ шттифт у центрі виїмки. Також розглянуто шестигранний профіль. Це стандартні головки, які можуть бути використані лише для роботи із кріпленням, що має шестикутні головки. Результати. Кріплення головкою Тогх більш надійне і довговічне і дозволяє досягти вражаючого крутного моменту.

Ключові слова: ториева головка, Tогх, навантаження, розрахунок, МКЕ, напруження.
Кравченко Роман Володимирович ${ }^{1}$, студент, т. 0501541902, romankravchenko1996@gmail.com

Богдан Дмитро Іванович ${ }^{1}$, к.т.н., доцент кафедри деталей машин і теорії механізмів та машин, тел. 380963103000, Phd.bogdan@ gmail.com

Повалясв Сергій Іванович ${ }^{1}$, к.т.н., доцент кафедри деталей машин і теорії механізмів та машин, тел. 380971992331, Povalyaevsi@ukr.net

${ }^{1}$ Харківський національний автомобільнодорожній університет, 61002, Україна, м. Харків, вул. Ярослава Мудрого, 25.

Comparison of the screw head loading capacity depending on the slot form

Abstract. Problem. For car repairs and other works with threaded fasteners, a convenient tool is often used - it is called end heads. Various types of splines, end heads, and screws have become widespread. The article describes the main geometrical dimensions, the nomenclature and applicability of the Hex and Torx slots and lists the advantages and disadvantages of each. The history of the formation of the current standard for specifying the slots is given. Goal. The aim of this work is to carry out a comparative analysis of the most used hexagonal socket head and Torx socket head, to assess their operational characteristics. Methodology. The connection of the bit with the screw head is considered in terms of the contact of the mating surfaces, the picture of the distribution of equivalent stresses in the screw head arising under the action of the torque applied to the tool is analyzed. Three-dimensional equivalent stress diagrams are given. The following variations of Torx spline options are considered: 1) Torx External - inverted Torx. It is used to reduce the size of the bolt head. 2) Torx Tamper Resistant is anti-vandal, denoted as TR. 3) Five-way Torx is one of the anti-vandal options. 4) Pentalobe is a separate chamomile-shaped slot, used in Apple electronics. 5) Torx Plus is an improved spline with star cut ends. It is denoted as IP (Internal Plus). Torx tool cannot work with Torx Plus hardware. 6) Torx Plus External is an external version of Torx Plus, denoted as EP (External Plus). The anti-vandal version of Torx Plus has five beams and a pin in the center of the recess. Also the hex profile is considered. These are standard heads, which can be used only for work with fasteners having hexagonal heads. Results. The fastener with this head is very reliable and durable and allows you to achieve impressive torque.

Key words: end head, Torx, load, calculation, FEM, stress.

Kravchenko Roman', student, tel. 0501541902, romankravchenko1996@gmail.com

Bogdan Dmitry ${ }^{1}$, Ph.D., Assoc. Prof. of Machine Parts and Theory of Mechanisms and Machines Department, tel. 0963103000, Phd.bogdan@gmail.com PovalyaevSergey $^{1}$, Ph.D., Assoc. Prof. of Machine Parts and Theory of Mechanisms and Machines Department, tel. 0971992331, Povalyaevsi@ukr.net ${ }^{1}$ Kharkov National Automobile and Highway University, 25, Yaroslava Mudrogo str., Kharkiv, 61002, Ukraine. 